\title{
Pulmonary Capillary Recruitment in Neonatal Lambs
}

\author{
LYNDA J. MEANS. WENDY L. HANSON. KYLE O. MOUNTS, AND WILTZ W. WAGNER. JK \\ Departments of Anesthesia. Pediatrics, and Physiolegy/Biophlysics, Indiana University. School of Medicine, \\ Indianapolis, Indiana $462(2)-5120$
}

\begin{abstract}
ABSTRACI. In species having lungs large enough to develop hydrostatic perfusion zones, increased pulmonary arterial pressure causes blood flow to be redistributed from the lower to the upper lung. The blood flow increase in the upper lung recruits capillaries and increases gas exchange surface area. There is disagreement, however, about whether such capillary recruitment occurs in young animals with small lungs. To investigate this issue, we used in vivo microscopy to directly study capillary perfusion in individual alveolar walls in the upper lungs of neonatal lambs and in older lambs with larger lungs. Pulmonary arterial pressure was elevated by airway hypoxia. In neonatal lambs ( $<10 \mathrm{~d}$ old; $n=7$ ), hypoxia increased pulmonary arterial pressure by $55 \%$ but did not cause capillary recruitment In older lambs (20-61 d old; $n=6$ ), hypoxia increased pulmonary arterial pressure by $40 \%$ and caused a $46 \%$ increase in recruited capillaries. These results support the hypothesis that capillary recruitment does not occur in newborn lambs when pulmonary arterial pressure increases and implies that there is limited gas exchange reserve. In older lambs, however, gas exchange reserve develops through recruitable capillaries as the lungs mature. (Pediatr Res 34: 596-599, 1993)
\end{abstract}

\section{Abbreviations}

CPI, capillary perfusion index

Increased pulmonary arterial pressure causes blood flow to be redistributed from the lower to the upper lung in animals with lungs that are large enough to have well-defined zones of perfusion (1-6). The increased upper lung blood flow recruits capillaries and increases total pulmonary gas exchange surface area (6). There is evidence that newborn lambs are capable of pulmonary capillary recruitment $(7,8)$, although several other studies found that capillary recruitment does not occur (9-12). Recruitment was not measured directly in any of these studies: rather, data were collected using several indirect techniques and the lambs that were used were in different age groups. The differing ages may be an important issue because the changes in the lung and its circulation are rapid and dramatic during the postnatal time period. For example, immediately after birth there is a large drop in pulmonary vascular resistance with a concomitant increase in flow and drop in pressure. This change is followed by regression of the fetal vascular pattern and an increase in lung volume caused by the rapid growth of alveoli. It seems likely therefore that these developmental changes could

Received March 22. 1993; accepted July 7. 1993.

Correspondence and reprint requests: W. W. Wagner, Jr., MS 374, 6.35 Barnhill Dr.. Indianapolis. IN $46202-5120$.

Supponed by NIII HL-36033. American Society of Anesthesiologists, James Whitcomb Riley Memorial Association. affect the capacity of the pulmonary circulation to recruit capillaries differently at different ages. In an attempt to determine directly whether capillary recruitment can occur in the newborn lamb and whether the capacity to recruit alters as the lamb matures, we used airway hypoxia to elevate pulmonary arterial pressure in lambs ranging in age from $2 \mathrm{~d}$ to $2 \mathrm{mo}$. Direct microscopic observations were made of the subpleural pulmonary capillaries in the uppermost lung where the potential for recruitment is maximal.

\section{MATERIALS AND METHODS}

Thirteen lambs (1.5-62 d old) were anesthetized by i.v. injection of pentobarbital sodium $(15-30 \mathrm{mg} / \mathrm{kg})$ dissolved in sterile $0.9 \%$ saline and maintained with intermittent doses $(5 \mathrm{mg} / \mathrm{kg})$ (13). The animals were intubated and mechanically ventilated by a constant volume ventilator (Harvard 607D. Harvard Apparatus, Inc., S. Natick, MA). Tidal volume and respiratory rate were adjusted to maintain arterial oxygen tension $>12 \mathrm{kPa}$. arterial carbon dioxide tension between 4.0 and $5.3 \mathrm{kPa}$, and arterial pH near 7.35 (System 1304 pH/Blood Gas Analyzer, Instrumentation Laboratory, Inc., Lexington, MA). Heart rates were determined from the ECG (model 410. Tektronix. Inc., Beaverton, OR). Temperatures were measured by a Yellow Springs Instrument Co. (Yellow Springs, OH) Tele-Thermometer and esophageal probe (LN2476-401). The lambs were warmed with a heating pad and infrared lamps. Polyethylene catheters (PE-160) were placed in a femoral artery and vein to determine cardiac outputs from indocyanine green dye dilution curves (Waters D402A densitometer and cuvette, Waters Associates, Milford, MA). A third polyethylene catheter was placed in the contralateral femoral artery to measure systemic arterial blood pressures and blood gases. Mean pulmonary arterial pressure was measured through a polyethylene catheter that had been guided fluoroscopically into the main pulmonary artery via the external jugular vein. Pressures were measured by Statham P23 Db transducers zeroed at the level of the left atrium and recorded on an eight-channel Gould Series 8000S recorder (Gould, Inc., Cleveland, $\mathrm{OH})$. Drugs were administered through a polyethylene catheter placed in the remaining femoral vein. The animals received $5 \%$ dextrose in Ringer's lactate $(15 \mathrm{~mL} / \mathrm{kg})$ i.v. to replace estimated fluid deficits from fasting overnight. The animals inspired a mixture of $35 \%$ oxygen and $65 \%$ nitrogen during control conditions and $12-16 \%$ oxygen, balance nitrogen, during hypoxia. Arterial pressures and cardiac outputs were measured during both experimental conditions.

To study the subpleural pulmonary microcirculation, a thoracotomy was performed in the 9 th left intercostal space and a transparent window was implanted by methods described in detail elsewhere $(1,3,14,15)$. The window was modified from previous designs that were made to be used in adult dogs (14). For use in the lambs, the window frame and rib flanges were reduced in size so that the window could fit into the small chest wall of the lamb, yet accommodate the microscope. After surgery, 
the animals were placed in the right lateral decubitus position on a microscope stand. The surface of the lung was illuminated by the collimated beam from a $200-\mathrm{W}$ mercury arc lamp heavily filtered to prevent tissue damage with a combination of dichroic infrared reflecting filters, broad band pass UV absorbing filters, and a narrow band pass $550-\mathrm{nm}$ interference filter to illuminate the lung only with the mercury green line. This wavelength is sufficiently absorbed by $\mathrm{Hb}$ to increase the contrast between the erythrocytes and the surrounding tissue (16) and is at the peak of retinal photopic spectral sensitivity, making it useful for visual observation. Alveolar capillaries were studied through the window with a Leitz Ultropak microscope $(\times 10$ eyepiece, $\times 11$ objective).

To quantify capillary recruitment, an image-splitting device (Leitz drawing attachment) was coupled to the microscope. This device permitted the observer to view simultaneously the magnified image of the surface of the lung and a sheet of drawing paper beside the microscope. A tracing was made of the outlines of four to 10 adjoining alveoli and of only those capillaries within the outlines that were perfused by red blood cells. Tracings were made during end expiration of perfused capillaries in the same alveolar walls during normoxic and hypoxic conditions. To determine whether the gas exchange surface area changed during each observation period, measurements were made of the total length of the perfused capillaries from the tracings using a digitizing pad (Houston Instrument Truegrid 1017 Austin. TX), planimetry software (SigmaScan, Jandel Scientific, San Rafael, CA), and an IBM AT computer. The area of the observed alveolar wall was also measured using the same system. Because subpleural alveolar facets in the upper lung of the lamb can be approximated by flat disks with an average diameter of $\sim 80 \mu \mathrm{m}$ and an area of $\sim 5000 \mu \mathrm{m}^{2}$, the alveolar wall area was divided by $5000 \mu \mathrm{m}^{2}$ to obtain the number of average walls in the area of observation [these dimensions were obtained from alveoli $(n=$ $311)$ measured in three animals]. This normalization permitted us to compare results between individual alveoli and between animals. Dividing the total length of perfused capillaries by the normalized alveolar area indicated how many times perfused capillaries crossed an average alveolar wall at its diameter. For example, a CPI of $80 \mu \mathrm{m}$ can be visualized as a capillary path length that would cross the diameter of an $80-\mu \mathrm{m}$ average alveolar facet once, whereas a CPI of $240 \mu \mathrm{m}$ would mean that an average alveolar wall could be crossed three times at its diameter. CPI is defined mathematically as follows:

$$
\text { CPI }(\mu \mathrm{m})=\frac{\sum \text { perfused capillary lenghts }(\mu \mathrm{m})}{\text { alveolar wall area }\left(\mu \mathrm{m}^{2}\right) / 5000\left(\mu \mathrm{m}^{2}\right)}
$$

This index has proven to be a useful indicator of capillary recruitment $(1-6,15)$.

At the conclusion of the studies, the lambs were given a large i.v. bolus of pentobarbital sodium followed by concentrated potassium chloride solution. The study protocol was approved by the Animal Care and Use Committee of the Indiana University School of Medicine.

Monotonic trends between variables were tested by the nonparametric ranking test of Spearman. Paired data from normoxic and hypoxic treatments were compared by the two-tailed $t$ test.

\section{RESULTS}

We successfully completed studies in 13 lambs (1.5-61 d old). The physiologic variables are summarized in Table 1. As expected, airway hypoxia caused pulmonary arterial pressure to increase significantly in all animals $(p<0.001)$. Capillary recruitment determined by the CPI during control conditions (normal pulmonary arterial pressure) and hypoxia (elevated pulmonary arterial pressure) is shown in Figure 1 for each of the lambs less than $10 \mathrm{~d}$ old. CPI did not change significantly [control $=257 \pm 12(\mathrm{SEM})$, hypoxia $=245 \pm 21 \mu \mathrm{m}, p=0.14]$, indicating that there was no capillary recruitment during hypoxia. In the older animals (Fig. 2), CPI increased by $46 \%$ [control $=194 \pm$ 26 , hypoxia $=283 \pm 27 \mu \mathrm{m}(p<0.01)]$, demonstrating that these animals were capable of recruiting capillaries in response to increased pulmonary arterial pressure. Technical difficulties prevented us from obtaining cardiac output measurements in all animals, especially the ones $>20 \mathrm{~d}$ old, which tended to become hemodynamically unstable when the green dye was injected. The measurements we successfully made in five lambs $<10 \mathrm{~d}$ old (control $=294 \pm 62 \mathrm{~mL} / \mathrm{min} / \mathrm{kg}$, hypoxia $=252 \pm 50 \mathrm{~mL} / \mathrm{min} /$ $\mathrm{kg}$ ) did not differ from the results of other investigators (17). In the youngest lamb (1.5 d old), hypoxia produced an increase in pulmonary arterial pressure by $23 \%$ with no change in cardiac output, whereas CPI decreased by $30 \%$. This finding may have been related to the presence of a patent ductus arteriosus, although functional closure of the ductus normally occurs after the first day of life in newborn lambs (18). If a patent ductus was present, the resulting right-to-left shunt and reduction of pulmonary blood flow would have accounted for the capillary derecruitment in this individual.

\section{DISCUSSION}

Our direct microscopic observations of the pulmonary capillaries in neonatal lambs showed that in the youngest lambs $(<10$ d old) capillary recruitment did not occur during hypoxia despite significant increases in pulmonary arterial pressure. In every one of the older lambs (>20 d old), there was considerable capillary recruitment when pulmonary arterial pressure rose. These findings suggest that the potential for recruitment begins to develop soon after birth and continues developing rapidly as the lamb grows. The recruited vessels were only capillaries and did not include arterioles and venules, which were always perfused. The finding that recruitment occurred exclusively in the capillaries is similar to the recruitment pattern found in the adult dog (15).

Because our observations were limited to the subpleural microcirculation, where the capillary network is less dense than in the interior (19-21), it is important to consider whether our conclusions are applicable to capillaries throughout the lung. Overholser $c t$ al. (22) analyzed three models of capillary anatomy (sheet flow, interconnected Y-tubes, and parallel channels) to investigate the effect of different segment densities on network resistance as might exist in surface v'ersus interior capillary beds. They concluded that the differences in network anatomy caused resistance differences that tended to offset each other in a way that resulted in all networks acting similarly. This analysis, combined with the lack of evidence that there are structural differences in the walls of subpleural and interior capillaries. makes it likely that capillary recruitment would occur similarly in both subpleural and interior capillary beds.

Capillary recruitment potential in lambs during the neonatal period has been studied by a number of investigators who used either the collection of lung lymph or the measurement of diffusing capacity to estimate changes in capillary volume. Both of these indirect methods have the advantage of sampling the entire perfused capillary bed. In the newborn lamb, the majority of investigators agree that capillary recruitment does not occur during hypoxia $(7,9,10)$, or with increased pulmonary blood flow $(11,12)$, or when left atrial pressure is increased $(7,11,12)$. One study of particular interest is that of Teague ct al. (8), who found that a $20 \%$ increase in pulmonary blood flow in $13-$ to 20 -d-old lambs caused $\sim 40 \%$ increase in lymph flow with an unchanged lymph-to-plasma protein ratio. This observation suggested that lung microvascular surface area expanded. The ages of their animals (13-20 d) fell in between our age groups and indicated that the ability to recruit began sometime shortly after the first week of life. In sum, the consensus from the literature strongly suggests that newborn lambs have a fully recruited capillary bed even at rest.

More mature lambs and sheep can recruit capillaries. That 
Table 1. Physiologic variables for two age groups of lambs*

\begin{tabular}{|c|c|c|c|c|c|c|}
\hline & \multicolumn{3}{|c|}{ Less than $10 \mathrm{~d}$ old } & \multicolumn{3}{|c|}{ More than $20 \mathrm{~d}$ old } \\
\hline & Control & Hypoxia & $p$ & Control & Hypoxia & $p$ \\
\hline $\mathrm{PaO}_{2}(\mathrm{kPa})$ & $17.6 \pm 1.2$ & $6.3 \pm 0.7$ & 0.001 & $18.7 \pm 2.8$ & $4.7 \pm 0.1$ & 0.001 \\
\hline $\mathrm{PaCO}_{2}(\mathrm{kPa})$ & $4.8 \pm 0.3$ & $4.9 \pm 0.4$ & 0.39 & $4.9 \pm 0.1$ & $4.7 \pm 0.1$ & 0.15 \\
\hline $\mathrm{pH}$ & $7.40 \pm 0.01$ & $7.40 \pm 0.01$ & 0.41 & $7.33 \pm 0.01$ & $7.34 \pm 0.02$ & 0.30 \\
\hline Ppa (kPa) & $2.9 \pm 0.3$ & $4.5 \pm 0.3$ & 0.001 & $2.1 \pm 0.3$ & $3.6 \pm 0.3$ & 0.001 \\
\hline $\mathrm{CPI}(\mu \mathrm{m})$ & $257 \pm 12$ & $245 \pm 21$ & 0.14 & $194 \pm 26$ & $283 \pm 27$ & 0.001 \\
\hline Paorta (kPa) & $7.6 \pm 0.3$ & $6.8 \pm 0.4$ & 0.02 & $11.6 \pm 0.7$ & $12.0 \pm 0.8$ & 0.27 \\
\hline $\mathrm{CO}(\mathrm{mL} / \mathrm{kg} / \mathrm{min})$ & $294 \pm 62$ & $252 \pm 50$ & 0.20 & & & \\
\hline HR (bpm) & $171 \pm 6$ & $166 \pm 10$ & 0.24 & $135 \pm 10$ & $145 \pm 15$ & 0.36 \\
\hline $\operatorname{Temp}\left({ }^{\circ} \mathrm{C}\right)$ & $36.9 \pm 0.3$ & $36.7 \pm 0.4$ & 0.42 & $39.4 \pm 0.3$ & $39.2 \pm 0.5$ & 0.12 \\
\hline
\end{tabular}

* All values are mean \pm SEM. $p$ values compare control and hypoxia for each age group. PaO $_{2}$, arterial oxygen tension: Paco, arterial carbon dioxide tension; pH, arterial pH; Ppa, pulmonary arterial pressure; CPI, capillary perfusion index; Paorta, systemic arterial pressure: CO, cardiac output; HR, heart rate; and Temp, esophageal temperature.

lambs $<10$ days old

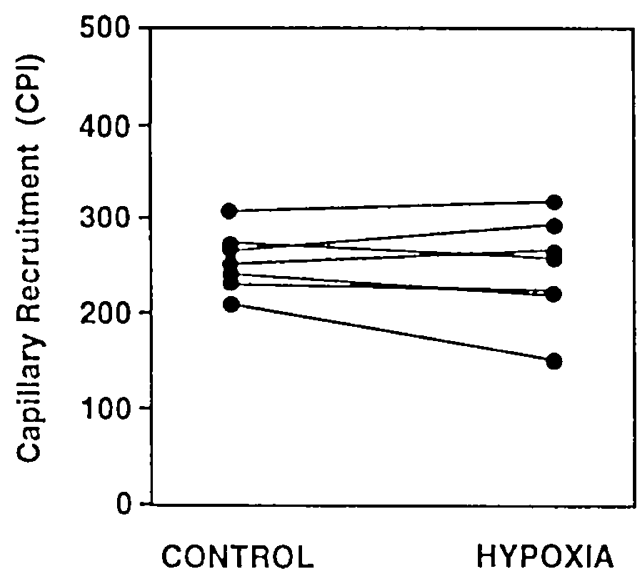

Fig. 1. Capillary recruitment in lambs less than $10 \mathrm{~d}$ old. Each line represents data from one animal. None of these animals recruited capillaries during hypoxia.

lambs $>20$ days old

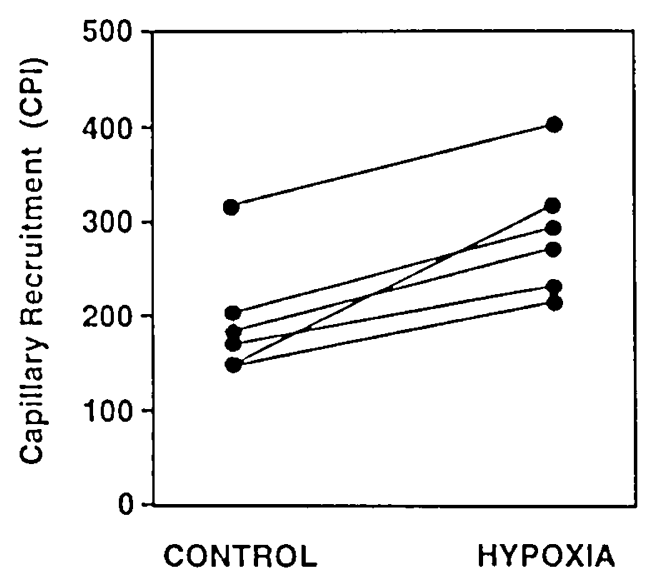

Fig. 2. Capillary recruitment in lambs more than $20 \mathrm{~d}$ old. Each line represents data from one animal. Every animal recruited capillaries during hypoxia.

comparison is clearly made in the elegant study of Nelin $e t$ al. (11), in which the diffusing capacity of the lung for carbon monoxide was measured in young lambs and adult sheep before and after pulmonary blood flow was increased or left atrial pressure was elevated. Neither maneuver increased diffusing capacity in the lambs, but both treatments increased capillary volume in the adult sheep.
Our observations support these indirect measures of capillary volume and enable us to specify that the increased capillary volume occurs via recruitment of individual capillary segments. The capillary recruitment reserve in the older lambs developed in a curious way. The younger lambs both during control and hypoxic conditions and the older lambs during hypoxic conditions all had CPI that were not significantly different from each other (Fig. 3). During control conditions in the older lambs, however, the CPI was significantly below all other measurements (Fig. 3), effectively leaving capillaries unperfused during control conditions. These reserve capillaries then became available for recruitment when pulmonary arterial pressure was increased. Our observations, combined with the work of other investigators, strongly suggest that as the lambs mature they develop the capacity to increase their capillary volume via capillary recruitment. Because this pulmonary circulatory change occurs so rapidly after birth, the age of the animals is an important concern when studies of the neonate are performed.

There are several cardiopulmonary alterations that occur during the neonatal period that could account for the development of the ability to recruit capillaries in the older lambs. A likely possibility is that, after birth, additional lung grows at a faster rate than cardiac output increases. Support for this idea comes from two sources. First, the morphometric analysis by Davies $2 t$ al. (23) showed that capillary volume quadrupled in the first 20 $\mathrm{d}$ of life and body weight doubled. Second, Pitt ct al. (24) showed that there was significant postnatal growth of the pulmonary microcirculation as reflected by the development of angiotensin converting enzyme. Another potential explanation for recruitment occurring only in older lambs is that in the youngest group of lambs, cardiac output did not increase with hypoxia. Teague et al. (8) showed that recruitment occurred when flow was

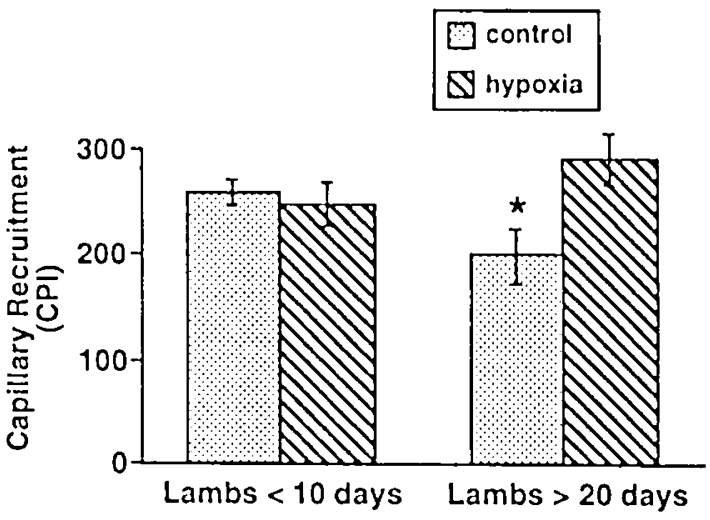

Fig. 3. The levels of capillary recruitment as measured by CPI were not significantly different from each other except for the older lambs during control conditions; in that case, the CPI was significantly lower $\left({ }^{*}, p<0.01\right)$ than any of the other measurements. 
increased in 13- to 20-d-old lambs. If output increased in the older lambs during hypoxia, this hemodynamic change could have explained the recruitment that occurred. It is unfortunate that technical difficulties prevented us from obtaining cardiac output measurements. Finally, we have shown in previous studies (6) in the adult dog that recruitment occurred in the upper lung if pulmonary arterial pressure was elevated and conversely fewer capillaries were perfused if pressure was reduced. The recruitment was caused by an upward redistribution of blood flow, a characteristic of airway hypoxia that also occurs in the lamb (9). As the lambs mature, the combination of lower pulmonary arterial pressure and the growth of additional lung wonld combine to reduce upper lung perfusion and leave capillaries available for recruitment. Although the design of the present study does not permit us to determine how much each of these changes contributes to the recruitment reserve in the older lambs, the following sequence seems plausible and is consistent with available data. In the first $10 \mathrm{~d}$ of life, the entire pulmonary capillary bed is completely recruited. This is caused by a combination of somewhat elevated pulmonary arterial pressures and a small lung. As perfusion pressures drops and the lung grows rapidly during the first 3 wk after birth, zone 2 perfusion conditions develop in the upper lung where pulmonary arterial pressure $>$ alveolar pressure $>$ pulmonary venous pressure. The reduced flow in this zone leaves some capillaries unperfused during basal conditions that can be recruited when pressure rises.

The high level of capillary perfusion was particularly impressive in the youngest lambs. The perfused capillaries were so close together that it was difficult to imagine there was room in the alveolar wall for unperfused capillary segments. A second perfusion characteristic of the younger lambs was the rapid transit of red blood cells across the capillary network. Although we did not measure those transit times, it appeared that the mean transit times were $<1 \mathrm{~s}$, which would likely place the most rapid transit times near the pulmonary diffusion limit that occurs when transit times drop below about $0.25 \mathrm{~s}(25)$. The rapid transit times and full recruitment combined in a way that left little reserve in the gas exchange vessels. The rapid development of pulmonary capillary reserve in the first 2 wk of life helps overcome the fragile gas exchange conditions that exist during the neonatal transition.

Acknowledgments. The authors thank R. G. Presson, Jr. and J. A. Graham for helpful criticism of the manuscript.

\section{REFERENCES}

1. Wagner Jr WW, Latham LP 1975 Pulmonary capillary recruitment during airway hypoxia in the dog. J Appl Physiol 39:900-905

2. Wagner Jr WW, Latham LP, Capen RL 1979 Capillary recruitment during hypoxia: role of pulmonary artery pressure. J Appl Physiol 47:383-387

3. Capen RL, Latham LP, Wagner Jr WW 1981 Diffusing capacity of the lung during hypoxia: role of capillary recruitment. J Appl Physiol 50:165-171

4. Dawson $A 1969$ Regional pulmonary blood flow in sitting and supine man during and after acute hypoxia. J Clin Invest 48:30 I-310

5. Dugard A. Naimark A 1967 Effect of hypoxia on distribution of pulmonary blood flow. J Appl Physiol 23:663-671

6. Capen RL. Wagner Jr WW 1982 Intrapulmonary blood flow redistribution during hypoxia increases gas exchange surface area. J Appl Physiol 52:15751581

7. Raj JU, Hazinski TA, Bland RD 1988 Effect of hypoxia on lung lymph flow in newborn lambs with left atrial hypertension. Am J Physiol 254:1448711493

8. Teague WG, Berner ME, Bland RD 1988 Effect of pulmonary perfusion on lung fluid filtration in young lambs. Am J Physiol 255:H1336-111341

9. Hansen TN, Le Blanc AL. Gest AL 1985 Hypoxia and angiotensin II infusion redistribute lung blood flow in lambs. J Appl Physiol 53:812-818

10. Bland RD, Bressack MA, Haberkern CM, Hansen TN 1980 Lung fluid balance in hypoxic, awake newborn lambs and mature sheep. Biol Neonate 38 : $221-228$

11. Nelin LN, Weardon ME, Hansen TN 1992 The effect of blood flow and left atrial pressure on the DLco in lambs and sheep. Respir Physiol 88:333-342

12. Feltes TF, Hansen TN 1989 Effects of aorticopulmonary shunt on lung fluid balance in the young lamb. Pediatr Res 26:94-97

13. Gray PR, McDonnell WN 1986 Anesthesia in goats and sheep. Part II. General anesthesia. The Compendium on Continuing Education 8:S127-S135

14. Wagner Jr WW 1969 Pulmonary microcirculatory observations in vivo under physiological conditions. J Appl Physiol 26:375-377

15. Hanson WL. Emhardt JD, Bartek JP, Latham LP. Checkley LL. Capen RL. Wagner Jr WW 1989 Site of recruitment in the pulmonary microcirculation. J Appl Physiol 66:2079-2083

16. Wagner Jr WW, Brinkman PD, Barker DB, Filley GF 1969 Erythrocyte photomicrography: contrast control by monochromatic transillumination. J Biol Photogr Assoc 37:156-162

17. Pitt BR. Lister G 1983 Pulmonary metabolic function in the awake lamb: effect of development and hypoxia. J Appl Physiol 55:383-391

18. Stahlman MT. Gray J, Young WC. Shephard FM 1967 Cardiovascular response of the neonatal lamb to hypoxia and hypercapnia. Am J Physiol 213:899-904

19. Guntheroth WG, Luchtel DL, Kawabori I 1982 Pulmonary microcirculation tubules rather than sheet and post. J Appl Physiol 53:510-515

20. Miller WS 1950 The Lung. Charles C Thomas, Springfield, IL

21. von Hayek H 1960 The Human Lung. Hafner Publishing Co.. New York

22. Overholser KA, Bhattacharya J, Staub NC 1982 Microvascular pressures in the perfused dog lung: comparison between theory and measurement. Microvase Res 23:67-76

23. Davies P. Reid L, Lister G, Pitt B 1988 Postnatal growth of the sheep lung: a morphometric study. Anat Rec 220:281-286

24. Pitt BR, Lister G. Davies P. Reid L 1987 Correlation of pulmonary angiotensin converting enzyme activity and capillary surface area during postnatal development. J Appl Physiol 62:2031-2041

25. Wagner PD 1977 Diffusion and chemical reaction in pulmonary gas exchange. Physiol Rev 57:257-312 